\title{
"Comparison of central corneal thickness in myopes, hyperopes and emmetropes of different age groups".
}

\author{
Lavanya Kalikivayi, Krishna Ratheesan, Venkataramana Kalikivayi*
}

Ahalia School of Optometry, Palakkad.

\begin{abstract}
Aim: The aim of this study is to compare the central corneal thickness between myopes, hyperopes and emmetropes of different age groups.

Materials and Methods: The study involves 156 eyes: 60 emmetropic subjects, 44 myopic subjects $(<$ $-8.0 \mathrm{D})$ and 52 hyperopic subjects (<+4.0 D). The Central Corneal Thickness (CCT) was measured with an ultrasound pachymeter and all the data entered in Microsoft excel for the statistical analysis.

Result: Mean CCT for myopic group $(n=44)$ was $539.3 \pm 30 \mu \mathrm{m}$, emmetropic group $(n=60)$ was $536 \pm$ $33 \mu \mathrm{m}$ and hyperopic group $(\mathrm{n}=52)$ was $540 \pm 49 \mu \mathrm{m}$. There were no statistically significant differences between the CCT's of myopic, hyperopic and emmetropic eyes for different age groups. No significant correlations were found between CCT and the amount of spherical equivalent in hyperopes and myopes.

Conclusion: There was no significant change in the CCT between myopes, hyperopes and emmetropes, and also no change in the central corneal thickness as the age progressed.
\end{abstract}

\section{Key words:}

Pachymeter, Myopia, Hyperopia, Emmetropia.

Accepted on October 12, 2018

\section{Introduction}

Cornea is the major refractive element of the eye where it contributes approximately two-thirds of optical refraction [1]. For a healthy cornea, the Central Corneal Thickness (CCT) varies between $0.49 \mathrm{~mm}$ to $0.57 \mathrm{~mm}$. CCT has a very important role in glaucoma. Thin average CCT results in under estimation of the true Intraocular Pressure (IOP) and thicker average CCT results in over estimation of IOP [2]. The detection and management of contact lens related complications and certain surgical procedures (such as astigmatic keratectomy, LASIK) rely on the accurate measurement of CCT $[3,4]$. The role of CCT in refractive errors was studied intensely over the years. Compared to emmetropic eye, myopic eye is longer and hyperopic eye is shorter. All the known possible changes in most of the refractive errors are located in the posterior segment like staphyloma, myopic conus, choroidal atrophy, thinning of the retina and sclera [1]. Changes in the anterior segment associated with refractive errors are still debatable.

Carney et al. found that the myopic cornea has a steeper central corneal curvature, [5] while Chang et al. found no correlation between corneal curvature and central corneal thickness [6]. Corneal pachymetry helps in the assessment of corneal oedema, effectivity of corneal refractive surgeries, suspicious glaucoma, bullous keratopathy, corneal oedema, posterior polymorphous dystrophy, Fuchs endothelial dystrophy and keratoconus during eye examination. Abnormally thick or thin measurements may indicate corneal anomalies. Pachymetry is an important procedure which needs to be measured prior to a LASER procedure to ensure sufficient corneal thickness is present, thereby preventing ectasias of the cornea. The measurements are essential, to decide on the setting of the baseline and the depth of the incision during the surgical procedure. Most surgeons measure the thickness peripheral to the clear zone and mark infero- temporally which is to be incised. CCT was found to be lower in patients with pseudoexfoliation syndrome and in primary open angle glaucoma [7,8]. The mean CCT of black children is thinner than that of white children [9]. The PITX2 mutation seen in Axenfeld- Rieger malformations result in the reduced corneal thickness.

As the CCT measurement makes an important examination procedure for patients undergoing LASIK, glaucoma treatment along with diagnosing corneal ectasia conditions, it is essential to know the normative data of the population to further plan the clinical treatment for a given patient. Documented differences between various refractive groups may contribute to the ongoing research in the field of glaucoma and LASIK. Hence the purpose of the study was to determine the correlation of CCT between different refractive errors and age groups.

\section{Materials and Methods}

The techniques for pachymetric measurements are ultrasonic techniques (conventional ultrasonic Pachymetry, ultrasound biomicroscopy), optical techniques (manual optical pachymetry, specular microscopy, OCT, optical coherence interferometry, confocal microscopy) and alternative measurement (pentacam, pachycam, ocular response analyzer). Ultrasound bio microscopy is a high resolution ultrasound 
machine which images anterior segment of the eye. It is useful in cases where cornea is opaque and various layers of cornea can be identified. Manual optical pachymetry contains two plain glass plates that split the image of the cornea parallelepiped. The two methodologies to measure the corneal thickness are just touch method and overlap method. Specular pachymetry involves measuring the distance between the anterior and posterior corneal surfaces. The thickness is determined by the focusing of light rays through front and back corneal surfaces. Slit scanning pachymetry incorporates measurements of anterior and posterior corneal elevations by comparing them to a best spherical fit. Multiple functions are assessed through this procedure viz, thickness profile, anterior and posterior topography, elevation and anterior chamber depth. Anterior segment OCT is useful in measuring and documenting the corneal flap thickness and residual stromal thickness by denoting in a colour map. Optical low coherence reflectometry is based on Michelson interferometer which uses a diode laser beam. The corneal thickness is measured to a one micron precision. Confocal microscopy assesses the thickness of each corneal layer by using computerized scanning system there by providing the total corneal thickness in the studied area. It also offers the possibility to visualize structures posterior to haze, scars or edema. Pentacam computes the thickness by a 3D rotating scheimpflug and displaces the color image over the entire area from limbus to limbus. Pachycam is a compact and portable non-contact pachymeter with a built in keratometer which can be mounted on slit lamp bio microscope and the image acquired is aligned with a $3 \mathrm{D}$ alignment screen.

A prospective study on the Comparison of central corneal thickness in myopes, hyperopes and emmetropes of age group 18-77 years was conducted in a tertiary eye hospital. All the subjects belong to southern India which represents the south Asian ethnicity. There were 90 females and 66 males in the group. Age is divided into three groups of 18-25 years, 26-40 years and more than 40 years. Institutes scientific review committee along with ethics committee approval was obtained before starting the study. Informed consent was obtained from all the patients. Total numbers of eyes were 156, out of which 60, 52 and 44 were emmetropes, hyperopes and myopes respectively. Myopes and hyperopes form the study groups, whereas emmetropes belong to control group. Both the groups were age and ethnicity matched. As myopes and hyperopes tend to have longer and shorter axial lengths respectively, can result in inappropriate treatment plan for patients undergoing LASIK, glaucoma treatment etc. Hence measurement of CCT plays an important role in these refractive errors. Emmetropia is defined as spherical equivalent between $+0.25 \mathrm{D}$ and -0.25 D. Myopia is characterized as spherical equivalent $\leq-0.50 \mathrm{D}$ and hyperopia as $\geq+0.50 \mathrm{D}$. The measurements were taken by a qualified Optometrist with at least two years of experience in comprehensive eye examination procedures. All the subjects underwent torch light examination, extraocular movement assessment, cover tests, objective and subjective refraction procedures. Later slit lamp examination was performed with direct ophthalmoscopy. As the subjects with corneal scar, corneal ectasias, corneal edema, keratitis, other ocular infections and systemic diseases influence the measurement of CCT, these subjects were excluded from the study.

The CCT measurements for these subjects were done with ultrasound pachymeter, as it is faster, simpler and portable, does not require a coupling medium and also easy to use. The readings were consistent and repeatable between observers thereby eliminating interobserver variation.

The ultrasound pachymetry instrument (Pac Scan 300 P) functions by measuring the amount of time (transit time) needed for ultrasound pulse pass from the one end of transducer to descemet's membrane and back to the transducer. The pachymeter used in our study is Pac Scan $300 \mathrm{P}$ and is shown in (Figure 1). Thus the corneal thickness is equal to (Transit time $\times$ Propagation velocity) $/ 2$. The standard speed of ultrasound in cornea is $1640 \mathrm{~m} / \mathrm{sec}$. The probe handle has piezoelectric crystal which emits ultra-sonic beam of $20 \mathrm{MHz}$ and also an interface between the cornea and transducer. The transducer sends ultrasound rays through the probe to the cornea and receives echoes from the cornea. Width of transducer beam is related to the size of the emitting crystal and of the width and configuration of the probe through which it passes. A wide probe tip and wide transducer beam reduces the accuracy of the corneal thickness reading at a single point. Therefore the diameter of the tip should not be more than 2 $\mathrm{mm}$ so as to diminish the area over which the ultrasound beam is spread and enables the observer to view exactly the position of the tip on the cornea. Surface of the tip should be smooth to avoid any injury to corneal epithelium.

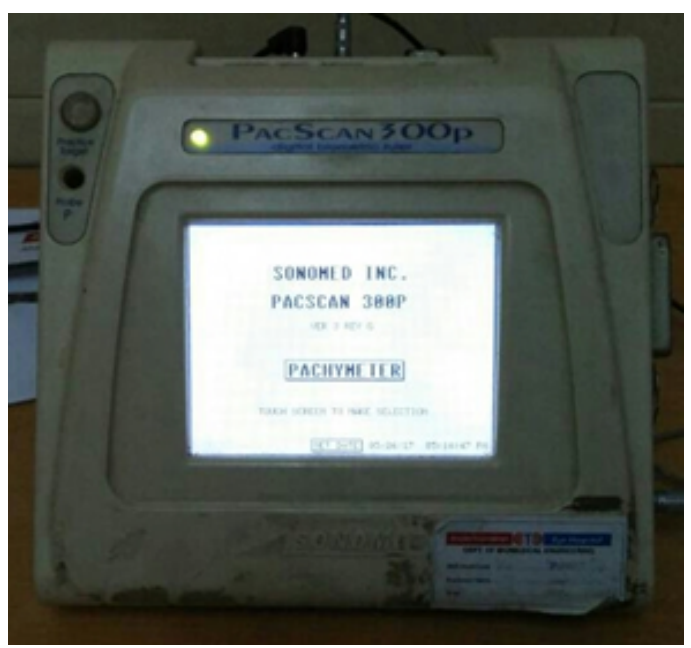

Figure 1. Ultrasound Pachymeter Pac Scan 300 P.

All the subjects underwent a comprehensive eye examination after which pachymetry was performed. The individual was positioned in an erect pose and the eyes were anesthetised with $4 \%$ lignocaine hydrochloride. A fixation target was presented and the probe was axially positioned at the centre of the cornea as shown in (Figure 2). The measurements were recorded and the data was entered in Microsoft Excel 2010. 
Citation: Lavanya K, Krishna R, Venkataramana K. "Comparison of central corneal thickness in myopes, hyperopes and emmetropes of different age groups". J Clin Ophthalmol. 2018;2(2):96-100.



Figure 2. Placing of the probe in the center of the cornea while during pachymetry.

All the data was entered in Microsoft excel software and Statistical Analysis was performed for descriptive statistics, independent t-test and regression analyses. $\mathrm{p}$ value less than 0.05 was considered as significant.

\section{Result}

The mean age for females was $31.06 \pm 15$ years and with a range of 18 to 73 years. For males, the mean age was $41.23 \pm$ 16 years with a range of 19 to 77 years. The mean age for 18-25 years for myopes, hyperopes and emmetropes was found to be $19.5 \pm 0.97$ years, $20.5 \pm 1.05$ years and $19.8 \pm 0.79$ years respectively. The mean age for 26-40 years for myopes, hyperopes and emmetropes was found to be $32.6 \pm 4.79$ years, $32.6 \pm 5.19$ years and $31.8 \pm 4.28$ years respectively. The mean age for more than 40 years for myopes, hyperopes and emmetropes was found to be $61.2 \pm 9.79$ years, $62.6 \pm 6.52$ years and $59.8 \pm 11.06$ years respectively. The mean spherical equivalent for myopes and hyperopes of age group 18 to 25 was $-1.33 \mathrm{D} \pm 1 \mathrm{D}$ (Range: $-0.50 \mathrm{D}$ to $-4.00 \mathrm{D}$ ) and $+0.62 \mathrm{D} \pm$ $0.43 \mathrm{D}$ (Range: $+0.50 \mathrm{D}$ to $+2.00 \mathrm{D}$ ) respectively. The mean spherical equivalent for myopes and hyperopes of age group 26 to 40 was $-1.15 \mathrm{D} \pm 0.59 \mathrm{D}$ (Range: $-0.50 \mathrm{D}$ to $-2.00 \mathrm{D}$ ) and $+0.72 \mathrm{D} \pm 0.49 \mathrm{D}$ (Range: $+0.50 \mathrm{D}$ to $+2.50 \mathrm{D}$ ) respectively. The mean spherical equivalent for myopes and hyperopes of age group above 40 was $-5.25 \mathrm{D} \pm 2.88 \mathrm{D}$ (Range: $-2.75 \mathrm{D}$ to $-7.75 \mathrm{D})$ and $+2.6 \mathrm{D} \pm 0.80 \mathrm{D}$ (Range: $+0.75 \mathrm{D}$ to $+3.75 \mathrm{D})$.

The mean CCT of myopes, emmetropes and hyperopes for the age group of 18 to 25 was found to be $534.5 \mu \mathrm{m}, 545.2 \mu \mathrm{m}$ and $548.7 \mu \mathrm{m}$, for an age group of 26 to 40 was found to be 541.9 $\mu \mathrm{m}, 530.6 \mu \mathrm{m}, 555 \mu \mathrm{m}$ respectively. The emmetropic, hyperopic and myopic mean CCT for the age group of $>40$ was found to be $534 \mu \mathrm{m}, 520.1 \mu \mathrm{m}$ and $550.7 \mu \mathrm{m}$ respectively. The mean CCT for emmetropes for all the three combined groups $(\mathrm{n}=156)$ was $536 \pm 33 \mu \mathrm{m}$, whereas the mean spherical equivalent and CCT for myopic group $(n=44)$ was found to be $-1.6 \mathrm{D} \pm 1.3 \mathrm{D}$ and $539.3 \pm 30 \mu \mathrm{m}$ respectively. The mean spherical equivalent and CCT of hyperopic group $(n=52)$ was found to be $+1.48 \pm 1.1 \mathrm{D}$ and $540 \pm 49 \mu \mathrm{m}$ respectively. The mean CCT for different age groups for emmetropes, myopes and hyperopes is given in (Table 1). An independent t-test revealed no statistical significance while comparing the mean CCT between these groups. Regression analyses revealed no significant correlation between CCT and the amount of spherical equivalent either in hyperope or myope groups. But the regression of myopic spherical equivalent with CCT gave a positive correlation and hyperopic spherical equivalent with CCT gave a negative correlation as shown in (Figure 3 and 4) respectively.

Table 1.The mean and standard deviation of CCT (in $\mu \mathrm{m}$ ) for different age groups in emmetropes, myopes and hyperopes.

\begin{tabular}{|l|l|l|l|}
\hline Age Group & Emmetropes & Myopes & Hyperopes \\
\hline $18-25$ & $545.2 \pm 29$ & $534.5 \pm 28$ & $548.7 \pm 69$ \\
\hline $26-40$ & $530.6 \pm 34$ & $541.9 \pm 29$ & $555 \pm 38$ \\
\hline$>40$ & $534 \pm 34$ & $550.7 \pm 52$ & $520.1 \pm 39$ \\
\hline Total & $536 \pm 33$ & $539.3 \pm 30$ & $540 \pm 49$ \\
\hline
\end{tabular}

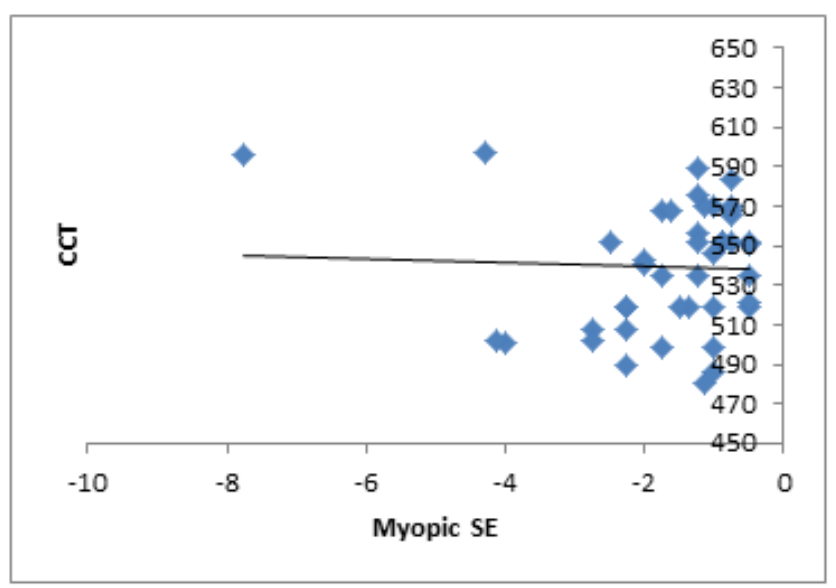

Figure 2. Positive correlation of CCT with myopic spherical equivalent.

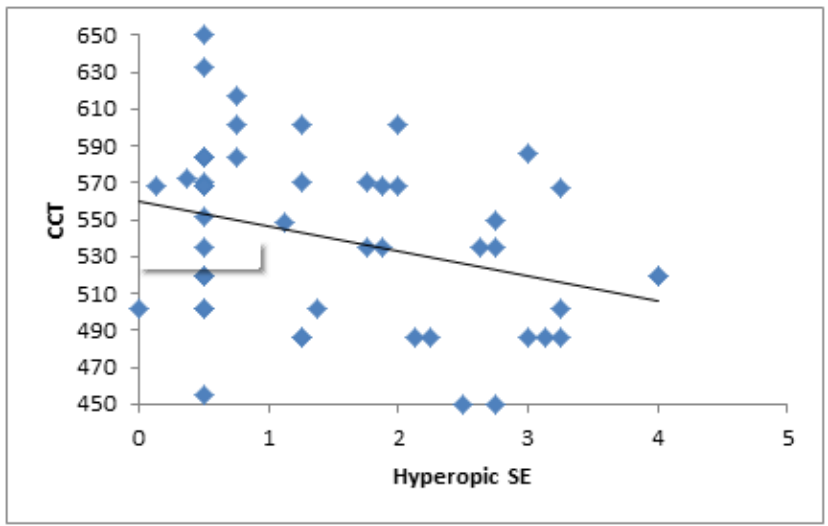

Figure 3. Negative Correlation of CCT with hyperopic spherical equivalent. 


\section{Discussion}

In this study, while comparing the Central Corneal Thickness in myopes, hyperopes and emmetropes of different age groups, no statistical significance was found and no variation in CCT was seen as age progressed.

In some studies, their results also revealed that there was no statistically significant difference between CCT in myopes, hypermetropes, and emmetropes which was also proved the same in our study [10-12]. In another study, CCT was measured with an Orbscan and only myopes were included [13]. They revealed that there was no correlation between the CCT and myopes which is similar to our work. In an earlier study, there was a multivariate linear regression which indicated that increasing age decrease the CCT by 0.28 micron whereas our work differed with this work [12].

Though the age range, sample size and the power range were vastly different between the studies, there was no correlation between CCT and refractive errors, which is in concurrent with our study.

Table 2. The mean CCT, age and sample size comparison for various countries.

\begin{tabular}{|c|c|c|c|c|}
\hline SI.no & Country & Mean CCT $(\mu \mathrm{m})$ & Age range in years & Sample size \\
\hline 1 & India & $540.6 \pm 35$ & $>40$ & 10033 \\
\hline 2 & Pakistan & $531.29 \pm 33$ & $16-73$ & 200 \\
\hline 3 & Malay & $530.87 \pm 30.79$ & August-16 & 54 \\
\hline 4 & China & $532.1 \pm 32.1$ & $>50$ & 6504 \\
\hline 5 & Spain & $548.21 \pm 30.7$ & Not available & 357 \\
\hline 6 & Sudan & $530.15 \pm 58$ & $<40$ & 94 \\
\hline 7 & Europe & $533 \pm 33$ & $5-15,32-60,61-82$ & Not available \\
\hline 8 & Nepal & $539 \pm 33$ & $>40$ & 2330 \\
\hline 9 & Egypt & $532.6 \pm 33$ & $16-70$ & 4368 \\
\hline 10 & Netherland & 537.4 & $>55$ & 395 \\
\hline 11 & Saudi & $545 \pm 27.6$ & Not available & 1140 \\
\hline 12 & Iraq & $543.95 \pm 32$ & $20-75$ & 418 \\
\hline 13 & Latin & $546.9 \pm 33$ & $>40$ & 1699 \\
\hline 14 & Singapore & 541.2 & $40-80$ & 3280 \\
\hline 15 & Korea & 553.6 & Not available & 803 \\
\hline 16 & Japan & $552 \pm 36$ & $62 \pm 13$ & 263 \\
\hline 17 & Turkey & $552.2 \pm 35$ & June-88 & 625 \\
\hline
\end{tabular}

On comparison of several studies, the mean CCT of various countries was found to be $540.5 \pm 1.9 \mu \mathrm{m}$, which shows a similarity to the mean CCT obtained in our study. Few countries such as India [14], Pakistan [15], Malay [16], China [17], Spain [18], Sudan [19], Europe [20], Nepal [21], Egypt [22] and Netherland [23] has a mean CCT ranging between $530 \mu \mathrm{m}$ to $540 \mu \mathrm{m}$. Saudi [24], Iraq [25], Latin [26] and Singapore [27] revealed a mean CCT with a range of $541 \mu \mathrm{m}$ to $550 \mu \mathrm{m}$. Korea [28], Japan [29] and Turkey [30] had a mean CCT range of $551 \mu \mathrm{m}$ to $560 \mu \mathrm{m}$. The mean CCT of various countries along with the respective sample size and age is given in (Table 2).

In spite of varying age range and sample size, the mean CCT remained same in all the study groups across various countries. All these subjects were emmetropes and other refractive errors or ocular pathologies were not considered for this mean CCT calculation. This work also revealed that axial length elongation or shortening does not influence CCT. Similarly CCT did not show any statistical significance between the refractive error groups (myopia and hyperopia) and its control group of emmetropia.

\section{Conclusion}

In this study, while comparing the Central Corneal Thickness in myopes, hyperopes and emmetropes of different age groups, no statistical significant differences were found between the groups and also no variation in CCT as the age progressed.

\section{References}

1. Pedersen L, Hjortdal J, Ehlers N. Central corneal thickness in high myopia. Acta Ophthalmol Scand. 2005;83(5): 539-42.

2. Doughty MJ, Zaman ML. Human corneal thickness and its impact on intraocular pressure measures: A review and meta-analysis approach. Survey of ophthalmology. Surv Ophthalmol. 2000;44(5):367-408.

3. Iskander NG, Penno EA, Peters NT, et al. Accuracy of Orbscan pachymetry measurements and DHG ultrasound pachymetry in primary laser in situ keratomileusis and LASIK enhancement procedures. J Cataract Refract Surg. 2001;27(5):681-5.

4. Lipshitz I, Dotan G. Central corneal pachymetry and LASIK. Ophthalmology. 2000;107(11):1967-8.

5. Carney LG, Mainstone JC, Henderson BA. Corneal topography and myopia. A cross-sectional study. Invest Ophthalmol Vis Sci. 1997;38(2):311-20.

6. Chang SW, Tsai IL, Hu FR, et al. The cornea in young myopic adults. Br J Ophthalmol. 2001;85(8):916-20.

7. Özcura F, Aydin S, Dayanir V. Central corneal thickness and corneal curvature in pseudoexfoliation syndrome with and without glaucoma. J Glaucoma. 2011;20(7):410-3.

8. Kim JW, Chen PP. Central corneal pachymetry and visual field progression in patients with open-angle glaucoma. Ophthalmology. 2004;111(11):2126-32.

9. Muir KW, Duncan L, Enyedi LB, et al. Central corneal thickness in children: Racial differences (black vs. white) and correlation with measured intraocular pressure. J Glaucoma. 2006;15(6):520-3.

10. Trupti S, Pathik B, Isha P, et al. Correlation of central corneal thickness and axial length in myopes, emmetropes, and hypermetropes. Int J Sci Study. 2016;3(12):206-9.

11. Chen MJ, Liu YT, Tsai CC, et al. Relationship between central corneal thickness, refractive error, corneal 
Citation: Lavanya K, Krishna R, Venkataramana K. "Comparison of central corneal thickness in myopes, hyperopes and emmetropes of different age groups". J Clin Ophthalmol. 2018;2(2):96-100.

curvature, anterior chamber depth and axial length. J Chin Med Assoc. 2009;72(3):133-7.

12. Lekskul M, Aimpun P, Nawanopparatskul B, et al. The correlations between central corneal thickness and age, gender, intraocular pressure and refractive error of aged 12-60 years old in rural Thai community. J Med Assoc Thai. 2005;88:S175-9.

13. Fam HB, How AC, Baskaran M, et al. Central corneal thickness and its relationship to myopia in Chinese adults. Br J Ophthalmol. 2006;90(12):1451-3.

14. Chua J, Tham YC, Liao J, et al. Ethnic differences of intraocular pressure and central corneal thickness: The Singapore epidemiology of eye diseases study. Ophthalmology. 2014;121(10):2013-22.

15. Channa R, Mir F, Shah MN, et al. Central corneal thickness of Pakistani adults. J Pak Med Assoc. 2009;59(4):225-8.

16. Heidary F, Gharebaghi R, Hitam WH, et al. Central corneal thickness and intraocular pressure in Malay children. PloS one. 2011;6(10):e25208.

17. Pan CW, Li J, Zhong $\mathrm{H}$, et al. Ethnic variations in central corneal thickness in a rural population in China: The yunnan minority eye studies. PloS one. 2015;10(8):e0135913.

18. Gros-Otero J, Arruabarrena-Sánchez C, Teus M. Central corneal thickness in a healthy Spanish population. Arch Soc Esp Oftalmol. 2011;86(3):73-6.

19. Mohamed NY, Hassan MN, Ali NM, et al. Central corneal thickness in Sudanese population. Sud J Ophthalmol. 2009;1(1):29-32.

20. Doughty MJ, Laiquzzaman M, Müller A, et al. Central corneal thickness in European (white) individuals, especially children and the elderly, and assessment of its possible importance in clinical measures of intraocular pressure. Ophthalmic Physiol Opt. 2002;22(6):491-504.

21. Thapa SS, Paudyal I, Khanal S, et al. Central corneal thickness and intraocular pressure in a Nepalese population: The Bhaktapur Glaucoma Study. J Glaucoma. 2012;21(7):481-5.

22. Mostafa EM. Central corneal thickness in southern Egypt. Int Ophthalmol. 2014;34(4):809-15.
23. Wolfs RC, Klaver CC, Vingerling JR, et al. Distribution of central corneal thickness and its association with intraocular pressure: The Rotterdam study. Am J Ophthalmol. 1997;123(6):767-72.

24. Al-Mezaine HS, Al-Obeidan S, Kangave D, et al. The relationship between central corneal thickness and degree of myopia among Saudi adults. Int Ophthalmol. 2009;29(5):373-8.

25. Kadhim YJ, Farhood QK. Central corneal thickness of Iraqi population in relation to age, gender, refractive errors, and corneal curvature: A hospital-based crosssectional study. Clin Ophthalmol. 2016;10:2369-76.

26. Hahn S, Azen S, Ying-Lai M, et al. Central corneal thickness in Latinos. Invest Ophthalmol Vis Sci. 2003;44(4):1508-12.

27. Su DH, Wong TY, Wong WL, et al. Singapore Malay eye study group. Diabetes, hyperglycemia, and central corneal thickness: The Singapore Malay eye study. Ophthalmology. 2008;115(6):964-68.e1.

28. Lee ES, Kim CY, Ha SJ, et al. Central corneal thickness of Korean patients with glaucoma. Ophthalmology. 2007;114(5):927-30.

29. Wu LL, Suzuki Y, Ideta R, et al. Central corneal thickness of normal tension glaucoma patients in Japan. Jpn J Ophthalmol. 2000;44(6):643-7.

30. Altinok A, Sen E, Yazici A, et al. Factors influencing central corneal thickness in a Turkish population. Curr Eye Res. 2007;32(5):413-9

\section{Correspondence to:}

Venkataramana Kalikivayi

Ahalia School of Optometry

Palakkad, Kerala 678557

India

Tel: 00919380764631

E-mail: kalikivayi@yahoo.com 